\title{
Inhibition of CD38 and supplementation of nicotinamide riboside ameliorate lipopolysaccharide-induced neuroinflammation in the hippocampus
}

\section{Jureepon Roboon}

Kanazawa University Graduate School of Medical Sciences: Kanazawa Daigaku Daigakuin lyaku Hokengaku Sogo Kenkyuka lyaku Hoken Gakuiki Igakurui

Tsuyoshi Hattori ( $\nabla$ thattori@staff.kanazawa-u.ac.jp )

Kanazawa University Graduate School of Medical Sciences: Kanazawa Daigaku Daigakuin lyaku Hokengaku Sogo Kenkyuka lyaku Hoken Gakuiki Igakurui https://orcid.org/0000-0002-8168-8710 Hiroshi Ishii

Kanazawa University Graduate School of Medical Sciences: Kanazawa Daigaku Daigakuin lyaku Hokengaku Sogo Kenkyuka lyaku Hoken Gakuiki Igakurui

\section{Mika Takarada-lemata}

Kanazawa University Graduate School of Medical Sciences: Kanazawa Daigaku Daigakuin lyaku Hokengaku Sogo Kenkyuka lyaku Hoken Gakuiki Igakurui

\section{Dinh Thi Nguyen}

\section{Kanazawa University}

\section{Collin D. Heer}

University of iowa, Free Radical and Radiation Biology Program

\section{Denis O'Mealley}

City of Hope National Medical Center Department of Medical Oncology and Therapeutics Research Charles Brenner

City of Hope National Medical Center

\section{Yasuhiko Yamamoto}

Kanazawa University Graduate School of Medical Sciences: Kanazawa Daigaku Daigakuin lyaku Hokengaku Sogo Kenkyuka lyaku Hoken Gakuiki Igakurui

\section{Hiroshi Okamoto}

Tohoku University School of Medicine: Tohoku Daigaku Daigakuin Igakukei Kenkyuka Igakubu

\section{Haruhiro Higashida}

Kanazawa University Graduate School of Medical Sciences: Kanazawa Daigaku Daigakuin lyaku Hokengaku Sogo Kenkyuka lyaku Hoken Gakuiki Igakurui

\section{Osamu Hori}




\section{Research}

Keywords: Neuroinflammation, NR, apigenin, astrocyte, microglia, LPS, neurodegeneration

Posted Date: December 28th, 2020

DOl: https://doi.org/10.21203/rs.3.rs-135107/v1

License: (c) (1) This work is licensed under a Creative Commons Attribution 4.0 International License.

Read Full License 


\section{Abstract}

\section{Background}

Neuroinflammation is initiated by the activation of the brain's innate immune system in response to an inflammatory challenge. Insufficient control of neuroinflammation leads to enhanced or prolonged pathology in neurological conditions, including multiple sclerosis, traumatic brain injury, and Alzheimer's disease. Nicotinamide adenine dinucleotide $\left(\mathrm{NAD}^{+}\right)$plays critical roles in cellular energy metabolism and calcium homeostasis. Our previous study demonstrated that the deletion of CD38, an enzyme that converts $\mathrm{NAD}^{+}$to calcium-mobilizing second messengers, increased $\mathrm{NAD}^{+}$levels in the brain and suppressed neuroinflammation, glial activation, and demyelination in a cuprizone-induced demyelination model mouse. However, the direct effects of $\mathrm{CD} 38$ and $\mathrm{NAD}^{+}$on neuroinflammation have not been clarified. Here, we investigated the effect of $C D 38$ inhibition and NAD ${ }^{+}$replacement in lipopolysaccharide (LPS)-induced neuroinflammation in mice.

\section{Methods}

To induce neuroinflammation, LPS $(10 \mu \mathrm{g})$ was injected into the lateral cerebral ventricle of wild-type (WT) and CD38 knockout (KO) male ICR mice. Apigenin, a flavonoid with CD38 inhibitory activity, $(40 \mathrm{mg} / \mathrm{kg})$ or nicotinamide riboside (NR), an $\mathrm{NAD}^{+}$precursor, $(400 \mathrm{mg} / \mathrm{kg})$ was administered intraperitoneally, once per day for 7 consecutive days, followed by LPS injection $6 \mathrm{~h}$ after the final administration of apigenin or NR. NAD levels in the hippocampus were measured, and neuroinflammation and neuronal damage in the hippocampus were assessed by qPCR, western blotting, and immunohistochemical analysis. In cell culture, mouse primary astrocytes and microglia were treated with apigenin $(50 \mu \mathrm{M}), \mathrm{NAD}^{+}(200 \mu \mathrm{M}), \mathrm{NR}(200 \mu \mathrm{M})$, or $78 \mathrm{c}(0.5 \mu \mathrm{M}$; a specific CD38 inhibitor), $4 \mathrm{~h}$ before LPS $(100 \mathrm{ng} / \mathrm{mL})$ stimulation. Proinflammatory cytokine expression and NF-kB nuclear translocation were assessed by qPCR and immunocytochemical analysis, respectively.

\section{Results}

CD38 expression in the cortex and hippocampus increased after LPS administration. Inflammatory responses and glial activation after LPS injection were significantly lower in CD38 KO mice than in WT mice. Pre-administration of apigenin or NR for $7 \mathrm{~d}$ increased NAD ${ }^{+}$levels in the brain and significantly suppressed the induction of cytokines and chemokines after LPS administration in mice. Moreover, LPSinduced glial activation and neurodegeneration were significantly suppressed under the same conditions. In cell culture, LPS-induced inflammatory responses were suppressed by treatment of primary astrocytes or microglia with apigenin, $\mathrm{NAD}^{+}, \mathrm{NR}$, or 78c. Finally, all these compounds suppressed the translocation of p65 to the nucleus by LPS in cultured microglia. 


\section{Conclusions}

CD38-mediated neuroinflammation is linked to $\mathrm{NAD}^{+}$consumption, and CD38 inhibition and NR supplementation may be beneficial for preventing neuroinflammation in pathological conditions.

\section{Background}

Neuroinflammation is a biological response initiated by tissue injury or infection in the central nervous system (CNS) to eliminate pathogenic components and induce tissue remodeling. However, insufficient control of neuroinflammation leads to the progression of many neurological conditions such as multiple sclerosis, traumatic brain injury, and Alzheimer's disease [1-3]. Glial cells, including microglia and astrocytes, are involved in the immune response in the CNS and play important roles in the development of neuroinflammation. It is well documented that sustained inflammatory responses cause the release of harmful mediators such as cytokines and chemokines from activated glial cells, and further affect neuronal cells by triggering neurodegeneration [4-7]. Therefore, suppression of neuroinflammation may be an important therapeutic target in neurological diseases.

CD38 is a type II and type III transmembrane protein [8] that catalyzes the formation of cyclic ADP-ribose (CADPR) and nicotinic acid adenine dinucleotide phosphate $\left(\mathrm{NAADP}^{+}\right)$from nicotinamide adenine dinucleotide $\left(\mathrm{NAD}^{+}\right)$and related metabolites [9] to mobilize calcium from intracellular stores [9-15]. CD38 has diverse functions. For example, it promotes the secretion of insulin from pancreatic beta cells and oxytocin from hypothalamic neurons, thereby promoting social behaviors that are deficient in mouse models of autism spectrum disorder (ASD) [16-21]. CD38 is also associated with glial cell functions. We previously demonstrated that under physiological conditions, CD38 regulates the maturation of astrocytes and differentiation of oligodendrocyte precursor cells using $\mathrm{NAD}^{+}$in the brain [22]. We also recently discovered that $\mathrm{CD} 38$ is crucially involved in the cuprizone-induced demyelination model in mice. CD38 expression was increased in the brain after cuprizone administration in a manner associated with the production of pro-inflammatory molecules, glial activation, and subsequent neurodegeneration. Deletion of CD38 suppresses these phenotypes by increasing NAD ${ }^{+}$levels in the brain [23]. CD38 has also been reported to play a critical role in the pathology of experimental autoimmune encephalomyelitis, another model of demyelination in mice [24].

$\mathrm{NAD}^{+}$is synthesized in four gene-encoded biosynthetic pathways from tryptophan, nicotinic acid (NA), nicotinamide (NAM), and nicotinamide riboside (NR) $[25,26]$. The NR biosynthetic pathway is both unique and highly efficient in rodents and humans [27] and corresponds to a biosynthetic pathway that is transcriptionally induced in heart failure [28] and central brain injury [29]. Moreover, in an Alzheimer's disease model, NR improved both cognitive function and protected against neurodegeneration [30, 31].

The NAD ${ }^{+}$level in the brain can also be increased by compounds that depress $\mathrm{NAD}^{+}$consumption. Thiazoloquin(az)olin(on)e, 78c, is a chemical that has a specific inhibitory effect on CD38 activity (CD38i) and has been reported to arrest age-related $\operatorname{NAD}^{+}$decline $[32,33]$. Similarly, a natural flavonoid 
apigenin (4'5,7-trihydroxyflavone) [34-36], was reported to inhibit CD38 enzymatic activity and increase intracellular $\mathrm{NAD}^{+}$levels [37]. The effects of these compounds on neuroinflammation have been tested separately, but not together in the same model. In this study, we investigated the anti-inflammatory effects of inhibition of CD38 and the supplementation of NR on lipopolysaccharide (LPS)-induced neuroinflammation.

\section{Methods}

\section{Chemicals}

The chemicals used in this study were as follows: LPS (20389-04, Nacalai Tesque, Kyoto, Japan), $\beta-N A D^{+}$ (24334-97, Nacalai Tesque), nicotinamide riboside (NR, NIAGEN, ChromaDex, CA, USA), apigenin (01618913, Wako, Osaka, Japan), and compound 78c (538763, Calbiochem, CA, USA).

\section{Animals and treatments}

Wild-type (WT) and CD38 knockout (KO) male ICR mice (10-11 week old) were used for the experiments (body weight; 30-36g). CD38 KO mice were generated as described previously and backcrossed for more than eight times [38]. All mice were housed in $345 \times 168 \times 140 \mathrm{~mm}$ cages in a temperature-controlled room $\left(24-25^{\circ} \mathrm{C}\right)$ with 12 -h light-dark cycles. Food and water were available ad libitum. LPS injection was performed as previously described [39]. In brief, $10 \mu \mathrm{g}$ LPS dissolved in $5 \mathrm{~m} \mathrm{~L}$ of sterile PBS or control sterile PBS was injected into the right lateral cerebral ventricle $(0.3 \mathrm{~mm}$ caudal to bregma and $-1.0 \mathrm{~mm}$ from lateral to midline at a depth of $3.0 \mathrm{~mm}$ ) using a microsyringe and stereotaxic coordinates. The animals were sacrificed at various time points as described in the Results section. Apigenin $(40 \mathrm{mg} / \mathrm{kg})$ or NR (400 mg/kg) was administered intraperitoneally once per day for 7 consecutive days, followed by LPS injection $6 \mathrm{~h}$ after the final administration of apigenin or NR. Mice were anesthetized and sacrificed at the indicated times after LPS injection. To avoid the effect of injection-mediated brain damage, the contralateral (left) side of the cerebral cortex or hippocampus was analyzed in all experiments. All animal experiments were performed in accordance with the guidelines and approved by the Animal Care and Use Committee of Kanazawa University (AP-194042).

\section{Reverse transcription quantitative polymerase chain reaction (RT-qPCR)}

RT-qPCR was performed as previously described [40]. In brief, total RNA was extracted from the cerebral cortex, hippocampus, or cultured cells using the FASTGene ${ }^{T M}$ RNA Basic Kit. (FG-80250, Nippon Genetics Co., Ltd), and cDNA was synthesized using the High-Capacity cDNA Reverse Transcription Kit (4368814, Applied Biosystems, Warrington, UK). Individual cDNA sequences were amplified using the Thunderbird ${ }^{\mathrm{TM}}$ SYBR qPCR ${ }^{\circledR}$ Mix (QPS-201, Toyobo Co., Ltd.) with specific primers. To measure differential expression, the comparative $\mathrm{Ct}$ method was used for data analyses in MxPro 4.10 (Agilent Technologies Inc.). The primer sequences are listed in Additional file 4: Table S1.

\section{Western blot analyses}


The hippocampal tissues or cultured cells were homogenized in a RIPA lysis buffer containing $1 \%$ NP- 40 , $0.1 \%$ sodium dodecyl sulfate (SDS), $0.2 \%$ deoxycholate, and protease inhibitors ( $1 \mathrm{mM}$ phenylmethylsulfonyl fluoride, $1 \mu \mathrm{g} / \mathrm{mL}$ aprotinin), and then centrifuged at 15,000 rpm for $15 \mathrm{~min}$. Denatured protein lysates were electrophoretically separated using SDS-polyacrylamide gel electrophoresis and proteins were transferred onto polyvinylidene fluoride membranes. Membranes were blocked in 5\% skimmed milk for 30 min and incubated with anti-CD38 (AF4947, R\&D systems, MN, USA, 1:500), anti-glial fibrillary acidic protein (GFAP) (G9269, Sigma, MO, USA, 1:5,000), anti-ionized calcium binding adaptor molecule 1 (Iba1) (019-19741, Wako, Osaka, Japan, 1:500) antibodies for $16 \mathrm{~h}$ at $4{ }^{\circ} \mathrm{C}$. Membranes were washed several times with Tris-buffered saline, 0.1\% Tween 20 (TBST) and incubated with anti-rabbit (SC-2004, 1:5,000, Santa Cruz Biotechnology), anti-mouse (SC-516102, 1:5,000, Santa Cruz Biotechnology), anti-goat (SC-2354, 1:1,000, Santa Cruz Biotechnology), or anti-rat (NA9350, Amersham Pharmacia biotech, 1:1000), and horseradish peroxidase-linked immunoglobulin G (Cell Signaling Technology, Tokyo, Japan) for $2 \mathrm{~h}$ at room temperature, and the membranes were washed several times with TBST. Immunoreactivity was detected using an enhanced chemiluminescence system (GE Healthcare Bio-Sciences, PA, USA). The intensity of each band was quantified using ImageJ software (https://imagej.nih.gov/ij/).

\section{Differential expression analysis of published microarray studies}

Microarray expression profiles and associated platform data were downloaded from the Gene Expression Omnibus (GEO) database for three studies: GSE49329, GSE102482, and GSE122815 using the "GEOquery" Bioconductor package [41]. Specific information regarding sample treatment and preparation can be found at the respective GEO accession numbers. Differentially expressed genes between control and LPS-treated cells or mice were identified using the GEO2R wrapper

(https://www.ncbi.nlm.nih.gov/geo/geo2r/) around the Bioconductor package "limma" [42]. P-values were adjusted to correct for false positives using the Benjamini-Hochberg method. Plots of NAD-related genes were generated using GraphPad Prism v8.

\section{Immunohistochemistry}

Mice were anesthetized with isoflurane and transcardially perfused with PBS followed by $4 \%$ paraformaldehyde (PFA). Brains were removed from mice and subjected to post-fixation in $4 \%$ PFA, followed by dehydration in $30 \%$ sucrose. Twenty micrometer-thick sections from $-3.14 \mathrm{~mm}-4.30 \mathrm{~mm}$ bregma were obtained using a cryostat (CM1950, Leica, Nussloch, Germany). To measure glial and neuronal cell loss in the mouse hippocampus sections were processed for immunostaining with antibodies against GFAP (1:1000), Iba1 (1:500), and neurofilament $\mathrm{H}$ non-phosphorylated (SMI-32) (801701, Biolegend, CA, USA 1:500), MAP2 (4542, Cell Signaling Technology, Tokyo, Japan 1:500). Subsequently, alexa488- (Thermo Fisher Scientific Inc.,1:200) or Cy3-conjugated secondary antibodies (Jackson ImmunoResearch Laboratories, Inc., PA, USA, 1:200) were used to visualize immunolabeling. Fluorescence images in the $\mathrm{CA} 1$ or $\mathrm{CA} 3$ of the hippocampus were obtained from 2 sections per mouse using a laser scanning confocal microscope EZ-C1 (Eclipse TE2000U, Nikon, Tokyo, Japan). The 
fluorescence intensity of each region of the hippocampus/total area was analyzed using ImageJ software.

\section{Analysis of $\mathrm{NAD}^{+}$levels in brain tissues}

After administration of apigenin or NR for $7 \mathrm{~d}$, hippocampal tissues were harvested from WT mice, and $\mathrm{NAD}^{+}$levels were measured with a commercially available NAD ${ }^{+} / \mathrm{NADH}$ assay kit (E2ND-100, bioassay System, SFC, USA) according to the manufacturer's protocol. The absorbance at $570 \mathrm{~nm}$ for each sample was measured using a Multiskan GO Microplate Spectrophotometer (Thermo Fischer Scientific, MA, USA).

\section{Glial cell cultures}

Astrocyte and microglial cultures were prepared from mixed glial cultures as previously described [23]. In brief, mixed glial cells were harvested from the cerebral cortices of WT neonatal mice (P1 to P3). After 14 $d$ of cultivation, cells were collected and incubated with CD11b MicroBeads (130-093-634, microbeads conjugated to monoclonal anti-human/mouse CD11b antibody, Miltenyi Biotec, Bergisch Gladbach, Germany) and applied to a magnetic column fitted into a MidiMACS ${ }^{T M}$ cell separator (Miltenyi Biotec). The cells were separated into CD11b-positive and CD11b-negative fractions. The CD11b-positive fraction, which contained microglia, was used for the experiments $24 \mathrm{~h}$ after plating. The CD11b-negative fraction, which contained astrocytes, was plated and used for experiments after reaching confluence.

\section{NF-kB nuclear translocation}

Cultured microglia were plated in eight chamber slides and treated with CD38 apigenin, NAD ${ }^{+}$, and NR for $4 \mathrm{~h}$ followed by LPS stimulation for $1 \mathrm{~h}$. Cells were then fixed with $4 \%$ PFA containing $0.2 \%$ NP- 40 . Cells were processed for immunocytochemistry experiments with antibodies against Iba1 and p65 (8242, Cell Signaling Technology, Tokyo, Japan 1:200). Cell nuclei were visualized with DAPI (Sigma). Immunohistochemical labeling was visualized with alexa488- or Cy3-conjugated secondary antibodies, and images were obtained using a laser scanning confocal microscope EZ-C1. The nuclear fluorescence intensity of p65 was determined by Integrated Density - (Area of selected cell $\times$ mean fluorescence of background) using ImageJ software.

\section{Statistical analysis}

The experimental results are expressed as mean \pm standard error of the mean (SEM), with the number of experiments indicated by "n." No statistical evaluations were performed to predetermine sample size, but our sample sizes were similar to those generally used in the field. One-way ANOVA followed by the TukeyKramer test or two-way ANOVA followed by Scheffe's $F$ test was used for the statistical analysis. $P$ values $<0.05$ were considered statistically significant.

\section{Results}




\section{CD38 expression was increased after LPS injection.}

We first investigated the expression of CD38 in LPS-induced neuroinflammation (Fig. 1a). Consistent with our recent report in the cuprizone-induced demyelinating model [23], RT-qPCR analysis revealed that the expression of $C d 38$ mRNA gradually increased in both the cerebral cortex and hippocampus, and reached significance after $6 \mathrm{~h}(p<0.01)$ and $12 \mathrm{~h}(p<0.05)$, respectively, of intracerebroventricular (i.c.v.) injection of LPS. Furthermore, the level of Cd38 mRNA expression was higher in the hippocampus than in the cerebral cortex at any time point after LPS injection (Fig. 1b). Western blot analysis confirmed the gradual increase in CD38 protein expression after LPS injection. The expression level of CD38 protein was also higher in the hippocampus than in the cerebral cortex (Fig. 1C). Furthermore, analysis of microarray data also showed elevated expression levels of CD38 mRNA in the brain after LPS injection and in the primary microglia after LPS stimulation (Additional file 2: Fig. S1). Interestingly, we found that other NAD+consuming enzymes, PARPs (poly (ADP-ribose) polymerases), were also significantly increased by induction of neuroinflammation (Additional file 2: Fig. S1). These results suggest that CD38 and other NAD-consuming molecules may be involved in LPS-induced neuroinflammation.

\section{LPS-induced neuroinflammation and glial activation are attenuated in CD38 KO mice.}

To evaluate the effect of CD38 deletion on LPS-induced neuroinflammation and glial activation, we analyzed the expression of pro-inflammatory genes and glia-associated genes after LPS injection (Fig. 2a). RT-qPCR analysis revealed that the expression of genes such as $I / 1 b, I / 16, \mathrm{Tnf}, \mathrm{Nos} 2, \mathrm{Cc} / 2$, and $C c / 3$ was robustly increased in WT mice $6 \mathrm{~h}$ after LPS injection (Fig. $2 \mathrm{~b}-\mathrm{g}$ ). In all cases except $/ / 1 \mathrm{~b}, \mathrm{mRNA}$ expression reached a peak $6 \mathrm{~h}$ after LPS injection and gradually decreased thereafter (Fig. $2 \mathrm{c}-\mathrm{g}$ ). In the case of $/ / 1 b$, the high level of expression continued to $12 \mathrm{~h}$ after LPS injection (Fig. 2b). The expression of these genes was significantly lower in CD38 KO mice than in WT mice (Fig. 2 b-g). The expression of mRNAs for Gfap and Iba 1 , an astrocytic and microglial marker, respectively, gradually increased and reached significantly high levels at $12 \mathrm{~h}$ and $24 \mathrm{~h}$, respectively, after LPS injection in WT mice. Expression of Gfap and Iba 1 was significantly lower in CD38 KO mice (Fig. 3a). Western blot analysis confirmed the increase of GFAP and Iba1 protein after LPS injection, but the level was significantly lower in CD38 KO mice than in WT mice $24 \mathrm{~h}$ after LPS injection (Fig. 3b). Immunohistochemical analysis further revealed that the immunoreactivity of GFAP and Iba 1 was clearly increased in both the CA1 and CA3 regions of the hippocampus $24 \mathrm{~h}$ after LPS injection, but the level was significantly lower in CD38 KO mice (Fig. 3c-d). These data indicate that deletion of CD38 suppresses LPS-induced neuroinflammation and glial activation.

\section{NR and apigenin ameliorated LPS-induced neuroinflammation and glial activation.}

The phenotypes in CD38 KO mice described above and in our recent study [23] suggest that pharmacological inhibition of CD38 and/or boosted brain NAD level may be capable of depressing pathological inflammation in neurological diseases. Therefore, we assessed the effect of apigenin, a natural flavonoid that acts as a CD38 inhibitor [37], and NR, an NAD precursor [26], on NAD levels in the 
context of LPS-injected neuroinflammation (Fig. 4a). The NAD ${ }^{+}$levels in the hippocampus were significantly higher in apigenin- or NR- administered mice than in control mice, and the levels were similar in both conditions (Fig. 4b). WT mice were pre-administered with apigenin or NR for $7 \mathrm{~d}$, and then injected with LPS $6 \mathrm{~h}$ after the final administration of each compound. RT-qPCR analysis revealed that the induction of inflammatory genes such as $/ / 1 b, \| / 6, T n f, N o s 2, C c / 2$, and $C c / 3$ was suppressed in compound-pre-administered mice than in control mice (Fig. 4c-h). Immunohistochemical analysis revealed enhanced levels of immunoreactivity for GFAP and lba1 $24 \mathrm{~h}$ after LPS injection, but levels were reduced in apigenin or NR pre-administered mice compared to the control group of mice (Fig. 5a-C). Furthermore, we examined $\mathrm{NAD}^{+}$levels and neuroinflammation in CD38 KO mice administered NR or apigenin (Additional file 3: Fig. S2). CD38 KO mice showed significantly higher NAD ${ }^{+}$levels than WT mice in any group (Additional file 3: Fig. S2b). Consistent with CD38 as the target of apigenin, apigenin did not increase the elevated NAD ${ }^{+}$level in CD38 KO mice. Additionally, CD38 KO mice exhibited lower expression of proinflammatory genes as shown in Fig. 2, and apigenin or NR did not further decrease these gene expression programs (Additional file 3: Fig. S2c-h). These results suggest that the levels of CD38 and $\mathrm{NAD}^{+}$determine the state of neuroinflammation and the activation of both astrocytes and microglia in the brain.

\section{NR and apigenin attenuated LPS-induced neurodegeneration}

As LPS-induced neuroinflammation often leads to neurodegeneration [43-46], the effect of apigenin and NR on neuronal damage was evaluated after LPS injection. Immunohistochemistry for nonphosphorylated neurofilament $\mathrm{H}$ (SMI32), a marker of damaged axons, revealed that neurodegeneration occurred within $24 \mathrm{~h}$ after LPS injection in both the CA1 and CA3 regions of the hippocampus, and the level was significantly lower in apigenin or NR pre-administered mice (Fig. 6a, b). Consistent with these results, immunohistochemistry for MAP2 revealed that the intensity of normal axons and dendrites decreased after LPS injection, and this decrease was partially recovered by apigenin or NR preadministration (Additional file 4: Fig. S3a, b). These results suggest that administration of NR or apigenin attenuated not only LPS-induced neuroinflammation but also subsequent LPS-induced neurodegeneration.

\section{$\mathrm{NR}$, apigenin and $78 \mathrm{c}$ reduced inflammatory response in vitro.}

Silencing of the cd38 gene and the addition of $\mathrm{NAD}^{+}$suppressed LPS-induced activation of astrocytes and microglia in vitro $[22,23]$, the effects of NR, apigenin, and 78c, the latter a CD38-specific inhibitor, on the inflammatory response were examined using cultured microglia and astrocytes. RT-qPCR analysis revealed that LPS strongly upregulated the expression of pro-inflammatory genes, such as $/ 11 \mathrm{~b}$, $/ 16$, Tnf, Nos2, Ccl2, and Cc/3 in microglia and/or astrocytes. In microglia, the expression of $/ / 1 \mathrm{~b}$ and $/ / 6$ was significantly reduced by all compounds, and that of Tnf and Nos 2 was significantly decreased by NAD ${ }^{+}$ and NR, and apigenin, respectively (Fig. 7a-d). In addition, in astrocytes, all compounds showed a tendency to suppress the induction of inflammatory genes, although the expression of $/ 16$ was significantly decreased by apigenin, and that of $\mathrm{Tnf}$ and $\mathrm{Ccl} 3$ was significantly reduced by $\mathrm{NAD}^{+}$after 
LPS injection. These results suggest that inhibition of CD38 and increased NAD ${ }^{+}$status directly suppress LPS-induced inflammatory responses, especially in microglia.

\section{NR, apigenin and 78c suppressed NF-kB signaling pathway.}

It is known that LPS binds to toll-like receptor 4, which activates the NF-kB cascade and consequently induces pro-inflammatory genes. To determine the relevance of CD38 inhibition and supplementation of $\mathrm{NAD}^{+}$in the NF-KB signaling pathway, the nuclear translocation of NF-KB was examined after LPS stimulation in cultured microglia. Immunocytochemical analysis revealed that the intensity of p65, a major component of NF-KB, in the nucleus was strongly increased $1 \mathrm{~h}$ after LPS stimulation. In contrast, it was significantly reduced by all the compounds (Fig. 8a, b). These results suggest that intracellular NAD ${ }^{+}$ suppresses LPS-induced NF-KB activation in microglia.

\section{Discussion}

In the current study, we investigated the effect of CD38 inhibition and supplementation of NAD ${ }^{+}$on LPSinduced neuroinflammation in mice. CD38 expression was increased both in the hippocampus and in the cerebral cortex after LPS injection. Deletion of CD38 decreased LPS-induced neuroinflammation and glial activation Consistently, pre-administration of apigenin and NR increased $\mathrm{NAD}^{+}$concentration in the brain, and suppressed LPS-induced inflammatory response, glial activation, and neurodegeneration. In primary cultured glial cells, compounds such as $78 \mathrm{c}$, apigenin, $N A D^{+}$, and NR effectively suppressed the activation of NF-KB and the induction of cytokines and chemokines after LPS treatment. These results suggest that inhibition of $\mathrm{CD} 38$ and supplementation with $\mathrm{NAD}^{+}$precursors both depress neuroinflammation and have therapeutic potential for some neurological diseases.

\section{The role of $\mathrm{NAD}^{+}$and $\mathrm{CD} 38$ in LPS-induced neuroinflammation}

To date, several studies, including ours, have suggested the involvement of CD38 in neuroinflammation. Deletion of CD38 in the APP.PS Alzheimer's disease model exhibited a significant reduction in A $\beta$ plaque load and microglia/macrophage accumulation in the brain compared with APP.PS mice with CD38 intact [47]. Our previous study also revealed that CD38 KO mice ameliorated demyelination, glial activation, and neuroinflammation in cuprizone-induced demyelination [23]. To explore the direct effects of CD38 deletion or inhibition, and supplementation of $\mathrm{NAD}^{+}$on neuroinflammation, we employed a mouse model of LPS-injection into the lateral cerebral ventricle in the current study. Our results demonstrated that CD38 deletion or inhibition, and supplementation with $\mathrm{NAD}^{+}$suppressed neuroinflammation at earlier stages (within $6 \mathrm{~h}$ ) after LPS administration in vivo (Fig. 2 and 4) and in vitro (Fig. 7 and 8), and these effects seem to be correlated with the increased level of $\mathrm{NAD}^{+}$in the brain (Fig. 4b) [23].

The biology of inflammation suggests that expression of inflammatory markers, including CD38, cytokines, and chemokines, constitutes a homeostatic attempt at controlling infection or environmental damage. However, uncontrolled inflammatory responses are clearly neurotoxic. The behavioral deficits of 
mice with CD38 deletion suggest that the formation of CD38-dependent second messengers, including CADPR [11] and NAADP [15], is required for oxytocin signaling, social intelligence, and parenting [17]. In the case of neuroinflammatory responses, we consider that the formation of CD38-dependent signals might induce such activities and/or elevated NAD might depress such activities.

Expression of glial markers such as GFAP and lba1 (Fig. 3 and 5), and those of neurodegeneration such as SMI32 (Fig. 6) were increased after LPS injection, and the levels were reduced in the conditions where CD38 was deleted or inhibited, and $\mathrm{NAD}^{+}$synthesis was supported by precursor supplementation. Since proinflammatory genes were elevated at earlier stages than glial markers after LPS administration, it is likely that the suppressive effects on glial activation are secondary to the anti-inflammatory effect of CD38 deletion or inhibition, and support of $\mathrm{NAD}^{+}$synthesis. However, we cannot rule out the possibility that CD38 directly regulates glial activation, since CD38 enhances GFAP expression during the postnatal development stages in vivo [22].

In contrast to the potential mechanisms by which CD38 and calcium release promote inflammatory gene expression, CD38 inhibition and NR supplementation both converge on elevated NAD ${ }^{+}$- mediated suppression of inflammatory responses. We recently showed that coronavirus infection induces transcriptional induction of a set of PARP-related genes that depleted cellular $\mathrm{NAD}^{+}$and that supplementation with $\mathrm{NAD}^{+}$precursors or pharmacological activation of $\mathrm{NAD}^{+}$synthesis can boost the activity of the highly transcribed PARP genes while providing partial protection against viral replication [48]. Here, we show that many of the same PARP genes are upregulated after LPS stimulation in vitro and in vivo (Additional file 1, Fig. S1). We therefore suggest that depressed activities of NAD-dependent enzymes (other than CD38) mediate inflammatory gene transcription. Three potential mediators are SIRT2, which reportedly prevents microglial activation by promoting NF-KB deacetylation [49], SIRT1, which potentially depresses NF-KB activity via deacetylation of p65/RelaA [50] and PARP10, which inhibit activation of NF-KB and downstream target genes in response to IL-1b and TNF-a in a manner that depends on its catalytic activity and poly-ubiquitin binding activities [51]. As glia-derived cytokines such as IFN-g and TNF-a synergistically promote neuronal degeneration with other toxic factors [52], the reduced levels of neuronal damage by NR or apigenin administration are likely attributed to decreased induction of pro-inflammatory molecules. Consistent with this proposed mechanism, three weeks of oral high-dose NR has been shown to depress the circulation of inflammatory cytokines in a small placebocontrolled trial of older men [53]. NAD ${ }^{+}$may also protect neurons directly because $\mathrm{NAD}^{+}$degradation has been directly linked to axonal degeneration. Sterile alpha and the TIR motif containing 1 (SARM1) initiates a local destruction program of axons through a process that involves the catastrophic depletion of axonal NAD ${ }^{+}[54]$.

These results are not without caveats. For example, apigenin showed stronger effects than other compounds such as NR and 78c to suppress $/ 16$ and Nos2 in cultured microglia and $/ / 6$ in cultured astrocytes (Fig. 7). Moreover, apigenin decreased cytokine expression even in LPS-injected CD38 KO mice 
(Fig. S2), suggesting that it has targets beyond CD38, which could include MAPK, Akt, JNK [55] or the GSK3b/Nrf2 signaling pathway [56].

\section{Future prospects}

Neuroinflammation is a contributing factor in various neurodegenerative diseases including Alzheimer's disease and Parkinson's disease $[55,57]$. Importantly, the vulnerability of hippocampal neurons that leads to cognitive impairment is strongly associated with neuroinflammation [58, 59]. In fact, apigenin and NR have been reported to have beneficial effects on neurodegenerative disease models [31, 60]. Apigenin has been reported to cross the blood-brain barrier (BBB) and increase NAD ${ }^{+}$concentration in the brain [61]. NR can also increase $\mathrm{NAD}^{+}$levels in the brains of Alzheimer's disease model mice when orally administered [30]. In ongoing work, we aim to clarify the neuroprotective mechanisms in disease models in order to better identify biomarkers that will enable successful clinical translation.

\section{Conclusions}

We identified novel effects of NR and apigenin on LPS-induced neuroinflammation. Testing these compounds in neurodegenerative diseases, aging, and neurodevelopmental disease models may be important for the development of new therapies for these diseases.

\section{Abbreviations}

BBB: Blood-brain barrier; CCL2: C-C motif chemokine ligand 2; CCL3: C-C motif chemokine ligand 3; CNS: central nervous system; CX: cortex; CADPR: cyclic ADP-ribose; DAPI: 4',6-diamidino-2-phenylindole dihydrochloride; GAPDH: glyceraldehyde 3-phosphate dehydrogenase; GFAP: glial fibrillary acidic protein; HPC: hippocampus; Iba1: ionized calcium binding adaptor molecule 1; Il1b: interleukin 1 beta; Il6: interleukin 6; i.c.v.: intracerebroventricular; i.p.: intraperitoneal; LPS: lipopolysaccharide; MAP2: microtubule-associated protein 2; $\mathrm{NAD}^{+}$: nicotinamide adenine dinucleotide; NA: nicotinic acid; NAM: nicotinamide; NR: nicotinamide riboside; Nos2: nitric oxide synthase 2; NF-kB: nuclear factor-kappa B; PBS: phosphate-buffered saline; PFA: paraformaldehyde; PARPs: poly (ADP-ribose) polymerases; RTqPCR: reverse transcription quantitative polymerase chain reaction; TNF: tumor necrosis factor

\section{Declarations}

\section{Acknowledgement}

We thank Mr. Takashi Tamatani for providing technical assistance and ChromaDex for Niagen.

\section{Authors' contributions}

$\mathrm{JR}, \mathrm{TH}, \mathrm{CB}$, and $\mathrm{OH}$ conceived and designed the experiments. JR, $\mathrm{HI}, \mathrm{MT}, \mathrm{CH}$, and DM performed the experiments and analyzed the data. JR, $\mathrm{TH}, \mathrm{CB}$, and $\mathrm{OH}$ wrote the paper. $\mathrm{JR}, \mathrm{TH}, \mathrm{CB}, \mathrm{YY}, \mathrm{HO}, \mathrm{HH}$, and $\mathrm{OH}$ 
discussed the data. All authors have read and approved the paper.

\section{Funding}

This work was supported by Grant-in Aid for Scientific Research (18KK0435, 18K06501 for TH, $18 \mathrm{KK} 0255,18 \mathrm{~K} 06500$ for $\mathrm{OH}$, and $18 \mathrm{~K} 06463$ for MT) from the Ministry of Education, Science, Technology, Sports and Culture of Japan, by Alfred E. Mann Family Foundation (for CB), by National Cancer Institute (F99CA245722 for CH) and by Kanazawa University SAKIGAKE Project 2018 and the CHOZEN project.

\section{Availability of data and materials}

All data generated or analyzed during this study are included in this article.

\section{Ethics approval and consent to participate}

All animals used in this study were treated humanely and were performed in strict accordance with the National Institutes of Health guidelines.

\section{Competing interests}

The authors declare that they have no competing interests.

\section{Consent for publication}

Not applicable.

\section{References}

1. Akiyama H, Barger S, Barnum S, Bradt B, Bauer J, Cole GM, Cooper NR, Eikelenboom P, Emmerling M, Fiebich BL, et al. Inflammation and Alzheimer's disease. Neurobiol Aging. 2000;21:383-421.

2. Lucas SM, Rothwell NJ, Gibson RM. The role of inflammation in CNS injury and disease. $\mathrm{Br} \mathrm{J}$ Pharmacol. 2006;147(Suppl 1):232-40.

3. Frischer JM, Bramow S, Dal-Bianco A, Lucchinetti CF, Rauschka H, Schmidbauer M, Laursen $H$, Sorensen PS, Lassmann $\mathrm{H}$. The relation between inflammation and neurodegeneration in multiple sclerosis brains. Brain. 2009;132:1175-89.

4. Liu W, Tang Y, Feng J. Cross talk between activation of microglia and astrocytes in pathological conditions in the central nervous system. Life Sci. 2011;89:141-6.

5. Norden DM, Trojanowski PJ, Villanueva E, Navarro E, Godbout JP. Sequential activation of microglia and astrocyte cytokine expression precedes increased lba-1 or GFAP immunoreactivity following systemic immune challenge. Glia. 2016;64:300-16.

6. Lian H, Litvinchuk A, Chiang AC, Aithmitti N, Jankowsky JL, Zheng H. Astrocyte-Microglia Cross Talk through Complement Activation Modulates Amyloid Pathology in Mouse Models of Alzheimer's 
Disease. J Neurosci. 2016;36:577-89.

7. Jo M, Kim JH, Song GJ, Seo M, Hwang EM, Suk K. Astrocytic Orosomucoid-2 Modulates Microglial Activation and Neuroinflammation. J Neurosci. 2017;37:2878-94.

8. Zhao YJ, Lam CM, Lee HC. The membrane-bound enzyme CD38 exists in two opposing orientations. Sci Signal. 2012;5:ra67.

9. Hogan KA, Chini CCS, Chini EN. The Multi-faceted Ecto-enzyme CD38: Roles in Immunomodulation, Cancer, Aging, and Metabolic Diseases. Front Immunol. 2019;10:1187.

10. Takasawa S, Nata K, Yonekura H, Okamoto H. Response. Science. 1993;262:585.

11. Takasawa S, Tohgo A, Noguchi N, Koguma T, Nata K, Sugimoto T, Yonekura H, Okamoto H. Synthesis and hydrolysis of cyclic ADP-ribose by human leukocyte antigen CD38 and inhibition of the hydrolysis by ATP. J Biol Chem. 1993;268:26052-4.

12. Lee HC. Multiplicity of $\mathrm{Ca} 2+$ messengers and $\mathrm{Ca} 2$ + stores: a perspective from cyclic ADP-ribose and NAADP. Curr Mol Med. 2004;4:227-37.

13. Guse AH. Second messenger function and the structure-activity relationship of cyclic adenosine diphosphoribose (cADPR). FEBS J. 2005;272:4590-7.

14. Malavasi F, Deaglio S, Funaro A, Ferrero E, Horenstein AL, Ortolan E, Vaisitti T, Aydin S. Evolution and function of the ADP ribosyl cyclase/CD38 gene family in physiology and pathology. Physiol Rev. 2008;88:841-86.

15. Nam TS, Park DR, Rah SY, Woo TG, Chung HT, Brenner C, Kim UH. Interleukin-8 drives CD38 to form NAADP from NADP(+) and NAAD in the endolysosomes to mobilize $\mathrm{Ca}(2+)$ and effect cell migration. FASEB J 2020.

16. Takasawa S, Nata K, Yonekura H, Okamoto H. Cyclic ADP-ribose in insulin secretion from pancreatic beta cells. Science. 1993;259:370-3.

17. Jin D, Liu HX, Hirai H, Torashima T, Nagai T, Lopatina O, Shnayder NA, Yamada K, Noda M, Seike T, et al. CD38 is critical for social behaviour by regulating oxytocin secretion. Nature. 2007;446:41-5.

18. Higashida H, Yokoyama S, Kikuchi M, Munesue T. CD38 and its role in oxytocin secretion and social behavior. Horm Behav. 2012;61:351-8.

19. Kim S, Kim T, Lee HR, Jang EH, Ryu HH, Kang M, Rah SY, Yoo J, Lee B, Kim Jl, et al. Impaired learning and memory in CD38 null mutant mice. Mol Brain. 2016;9:16.

20. Okamoto H, Takasawa S, Yamamoto Y. From insulin synthesis to secretion: Alternative splicing of type 2 ryanodine receptor gene is essential for insulin secretion in pancreatic beta cells. Int J Biochem Cell Biol. 2017;91:176-83.

21. Gerasimenko M, Cherepanov SM, Furuhara K, Lopatina O, Salmina AB, Shabalova AA, Tsuji C, Yokoyama S, Ishihara K, Brenner C, Higashida H. Nicotinamide riboside supplementation corrects deficits in oxytocin, sociability and anxiety of CD157 mutants in a mouse model of autism spectrum disorder. Sci Rep. 2020;10:10035. 
22. Hattori T, Kaji M, Ishii $H$, Jureepon R, Takarada-lemata M, Minh Ta H, Manh Le T, Konno A, Hirai H, Shiraishi Y, et al. CD38 positively regulates postnatal development of astrocytes cell-autonomously and oligodendrocytes non-cell-autonomously. Glia. 2017;65:974-89.

23. Roboon J, Hattori T, Ishii H, Takarada-lemata M, Le TM, Shiraishi Y, Ozaki N, Yamamoto Y, Sugawara A, Okamoto H, et al. Deletion of CD38 Suppresses Glial Activation and Neuroinflammation in a Mouse Model of Demyelination. Front Cell Neurosci. 2019;13:258.

24. Herrmann MM, Barth S, Greve B, Schumann KM, Bartels A, Weissert R. Identification of gene expression patterns crucially involved in experimental autoimmune encephalomyelitis and multiple sclerosis. Dis Model Mech. 2016;9:1211-20.

25. Bogan KL, Brenner C. Nicotinic acid, nicotinamide, and nicotinamide riboside: a molecular evaluation of NAD + precursor vitamins in human nutrition. Annu Rev Nutr. 2008;28:115-30.

26. Bieganowski P, Brenner C. Discoveries of nicotinamide riboside as a nutrient and conserved NRK genes establish a Preiss-Handler independent route to NAD + in fungi and humans. Cell. 2004;117:495-502.

27. Trammell SA, Schmidt MS, Weidemann BJ, Redpath P, Jaksch F, Dellinger RW, Li Z, Abel ED, Migaud $\mathrm{ME}$, Brenner $\mathrm{C}$. Nicotinamide riboside is uniquely and orally bioavailable in mice and humans. Nat Commun. 2016;7:12948.

28. Diguet N, Trammell SAJ, Tannous C, Deloux R, Piquereau J, Mougenot N, Gouge A, Gressette M, Manoury B, Blanc J, et al. Nicotinamide Riboside Preserves Cardiac Function in a Mouse Model of Dilated Cardiomyopathy. Circulation. 2018;137:2256-73.

29. Vaur P, Brugg B, Mericskay M, Li Z, Schmidt MS, Vivien D, Orset C, Jacotot E, Brenner C, Duplus E. Nicotinamide riboside, a form of vitamin B3, protects against excitotoxicity-induced axonal degeneration. FASEB J. 2017;31:5440-52.

30. Gong B, Pan Y, Vempati P, Zhao W, Knable L, Ho L, Wang J, Sastre M, Ono K, Sauve AA, Pasinetti GM. Nicotinamide riboside restores cognition through an upregulation of proliferator-activated receptorgamma coactivator 1 alpha regulated beta-secretase 1 degradation and mitochondrial gene expression in Alzheimer's mouse models. Neurobiol Aging. 2013;34:1581-8.

31. Hou Y, Lautrup S, Cordonnier S, Wang Y, Croteau DL, Zavala E, Zhang Y, Moritoh K, O'Connell JF, Baptiste BA, et al. NAD(+) supplementation normalizes key Alzheimer's features and DNA damage responses in a new AD mouse model with introduced DNA repair deficiency. Proc Natl Acad Sci U S A. 2018;115:E1876-85.

32. Tarrago MG, Chini CCS, Kanamori KS, Warner GM, Caride A, de Oliveira GC, Rud M, Samani A, Hein KZ, Huang R, et al. A Potent and Specific CD38 Inhibitor Ameliorates Age-Related Metabolic Dysfunction by Reversing Tissue NAD(+) Decline. Cell Metab. 2018;27:1081-95 e1010.

33. Chini CCS, Peclat TR, Warner GM, Kashyap S, Espindola-Netto JM, de Oliveira GC, Gomez LS, Hogan $\mathrm{KA}$, Tarrago MG, Puranik AS, et al. CD38 ecto-enzyme in immune cells is induced during aging and regulates NAD(+) and NMN levels. Nat Metab. 2020;2:1284-304. 
34. Nijveldt RJ, van Nood E, van Hoorn DE, Boelens PG, van Norren K, van Leeuwen PA. Flavonoids: a review of probable mechanisms of action and potential applications. Am J Clin Nutr. 2001;74:41825.

35. Shukla S, Gupta S. Apigenin: a promising molecule for cancer prevention. Pharm Res. 2010;27:96278.

36. Venigalla M, Gyengesi E, Munch G. Curcumin and Apigenin - novel and promising therapeutics against chronic neuroinflammation in Alzheimer's disease. Neural Regen Res. 2015;10:1181-5.

37. Escande C, Nin V, Price NL, Capellini V, Gomes AP, Barbosa MT, O'Neil L, White TA, Sinclair DA, Chini EN. Flavonoid apigenin is an inhibitor of the NAD + ase CD38: implications for cellular NAD + metabolism, protein acetylation, and treatment of metabolic syndrome. Diabetes. 2013;62:1084-93.

38. Kato I, Yamamoto Y, Fujimura M, Noguchi N, Takasawa S, Okamoto H. CD38 disruption impairs glucose-induced increases in cyclic ADP-ribose, [Ca2+]i, and insulin secretion. J Biol Chem. 1999;274:1869-72.

39. Zhao J, Bi W, Xiao S, Lan X, Cheng X, Zhang J, Lu D, Wei W, Wang Y, Li H, et al. Neuroinflammation induced by lipopolysaccharide causes cognitive impairment in mice. Sci Rep. 2019;9:5790.

40. Hattori T, Shimizu S, Koyama Y, Yamada K, Kuwahara R, Kumamoto N, Matsuzaki S, Ito A, Katayama T, Tohyama M. DISC1 regulates cell-cell adhesion, cell-matrix adhesion and neurite outgrowth. Mol Psychiatry. 2010;15(778):798-809.

41. Davis S, Meltzer PS. GEOquery: a bridge between the Gene Expression Omnibus (GEO) and BioConductor. Bioinformatics. 2007;23:1846-7.

42. Ritchie ME, Phipson B, Wu D, Hu Y, Law CW, Shi W, Smyth GK. limma powers differential expression analyses for RNA-sequencing and microarray studies. Nucleic Acids Res. 2015;43:e47.

43. Qin L, Wu X, Block ML, Liu Y, Breese GR, Hong JS, Knapp DJ, Crews FT. Systemic LPS causes chronic neuroinflammation and progressive neurodegeneration. Glia. 2007;55:453-62.

44. Pintado C, Gavilan MP, Gavilan E, Garcia-Cuervo L, Gutierrez A, Vitorica J, Castano A, Rios RM, Ruano D. Lipopolysaccharide-induced neuroinflammation leads to the accumulation of ubiquitinated proteins and increases susceptibility to neurodegeneration induced by proteasome inhibition in rat hippocampus. J Neuroinflammation. 2012;9:87.

45. Deng X, Li M, Ai W, He L, Lu D, Patrylo PR, Cai H, Luo X, Li Z, Yan X. Lipolysaccharide-Induced Neuroinflammation Is Associated with Alzheimer-Like Amyloidogenic Axonal Pathology and Dendritic Degeneration in Rats. Adv Alzheimer Dis. 2014;3:78-93.

46. Wang Y, Ni J, Zhai L, Gao C, Xie L, Zhao L, Yin X. Inhibition of activated astrocyte ameliorates lipopolysaccharide- induced depressive-like behaviors. J Affect Disord. 2019;242:52-9.

47. Blacher E, Dadali T, Bespalko A, Haupenthal VJ, Grimm MO, Hartmann T, Lund FE, Stein R, Levy A. Alzheimer's disease pathology is attenuated in a CD38-deficient mouse model. Ann Neurol. 2015;78:88-103.

48. Heer CD, Sanderson DJ, Voth LS, Alhammad YMO, Schmidt MS, Trammell SAJ, Perlman S, Cohen MS, Fehr AR, Brenner C. Coronavirus infection and PARP expression dysregulate the NAD 
Metabolome: an actionable component of innate immunity. J Biol Chem 2020.

49. Pais TF, Szego EM, Marques O, Miller-Fleming L, Antas P, Guerreiro P, de Oliveira RM, Kasapoglu B, Outeiro TF. The NAD-dependent deacetylase sirtuin 2 is a suppressor of microglial activation and brain inflammation. EMBO J. 2013;32:2603-16.

50. Caon I, Bartolini B, Moretto P, Parnigoni A, Carava E, Vitale DL, Alaniz L, Viola M, Karousou E, De Luca $G$, et al: Sirtuin 1 reduces hyaluronan synthase 2 expression by inhibiting nuclear translocation of NFkB and expression of the long-non coding RNA HAS2-AS1. J Biol Chem 2020.

51. Verheugd P, Forst AH, Milke L, Herzog N, Feijs KL, Kremmer E, Kleine H, Luscher B. Regulation of NFkappaB signalling by the mono-ADP-ribosyltransferase ARTD10. Nat Commun. 2013;4:1683.

52. Suzumura A, Takeuchi H, Zhang G, Kuno R, Mizuno T. Roles of glia-derived cytokines on neuronal degeneration and regeneration. Ann N Y Acad Sci. 2006;1088:219-29.

53. Elhassan YS, Kluckova K, Fletcher RS, Schmidt MS, Garten A, Doig CL, Cartwright DM, Oakey L, Burley CV, Jenkinson N, et al. Nicotinamide Riboside Augments the Aged Human Skeletal Muscle NAD (+) Metabolome and Induces Transcriptomic and Anti-inflammatory Signatures. Cell Rep. 2019;28:1717-28 e1716.

54. Essuman K, Summers DW, Sasaki Y, Mao X, DiAntonio A, Milbrandt J. The SARM1 Toll/Interleukin-1 Receptor Domain Possesses Intrinsic NAD(+) Cleavage Activity that Promotes Pathological Axonal Degeneration. Neuron. 2017;93:1334-43 e1335.

55. Ginwala R, Bhavsar R, Chigbu DI, Jain P, Khan ZK: Potential Role of Flavonoids in Treating Chronic Inflammatory Diseases with a Special Focus on the Anti-Inflammatory Activity of Apigenin. Antioxidants (Basel) 2019, 8.

56. Chen P, Huo X, Liu W, Li K, Sun Z, Tian J. Apigenin exhibits anti-inflammatory effects in LPSstimulated BV2 microglia through activating GSK3beta/Nrf2 signaling pathway. Immunopharmacol Immunotoxicol 2019:1-8.

57. Glass CK, Saijo K, Winner B, Marchetto MC, Gage FH. Mechanisms underlying inflammation in neurodegeneration. Cell. 2010;140:918-34.

58. Semmler A, Widmann CN, Okulla T, Urbach H, Kaiser M, Widman G, Mormann F, Weide J, Fliessbach $\mathrm{K}$, Hoeft A, et al. Persistent cognitive impairment, hippocampal atrophy and EEG changes in sepsis survivors. J Neurol Neurosurg Psychiatry. 2013;84:62-9.

59. Tan H, Cao J, Zhang J, Zuo Z. Critical role of inflammatory cytokines in impairing biochemical processes for learning and memory after surgery in rats. J Neuroinflammation. 2014;11:93.

60. Zhao L, Wang JL, Liu R, Li XX, Li JF, Zhang L. Neuroprotective, anti-amyloidogenic and neurotrophic effects of apigenin in an Alzheimer's disease mouse model. Molecules. 2013;18:9949-65.

61. Balez R, Steiner N, Engel M, Munoz SS, Lum JS, Wu Y, Wang D, Vallotton P, Sachdev P, O'Connor M, et al. Neuroprotective effects of apigenin against inflammation, neuronal excitability and apoptosis in an induced pluripotent stem cell model of Alzheimer's disease. Sci Rep. 2016;6:31450.

\section{Figures}


Fig. 1
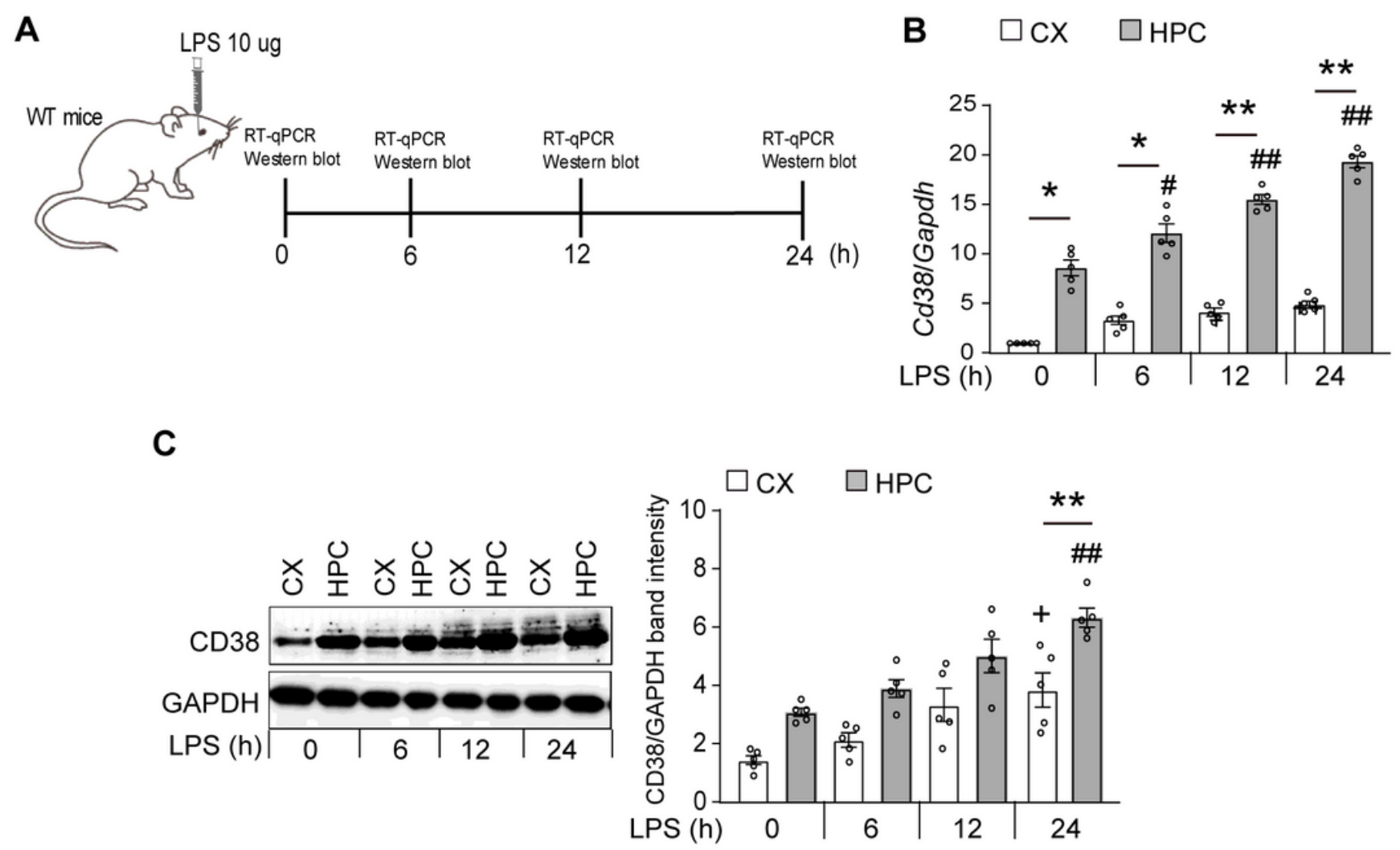

Figure 1

CD38 expression was increased after LPS injection. (a) The treatment scheme and timeline of analysis. (b) RT-qPCR analysis for the expression levels of Cd38 mRNA in the cortex (CX) and hippocampus (HPC) $0,6,12,24 \mathrm{~h}$ after LPS injection. $\mathrm{n}=5$. (c) Western blotting analysis with antibodies against CD38 and glyceraldehyde 3-phosphate dehydrogenase (GAPDH) in the CX and HPC at different time point after LPS injection. The graph depicts the relative optical density of CD38 normalized to GAPDH, $n=5$. Data represent means \pm SEM. $P$ values are determined by two-way ANOVA followed by Scheffe's $F$ test. $+p<$ 0.05 and $++p<0.01$ vs $0 \mathrm{~h}$ of LPS in the CX. $\# p<0.05$ and \#\#p $<0.01$ vs 0 h of LPS in the HPC. ${ }^{*} p<0.05$ and ${ }^{*} \mathrm{p}<0.01$ between the CX and HPC. 
A

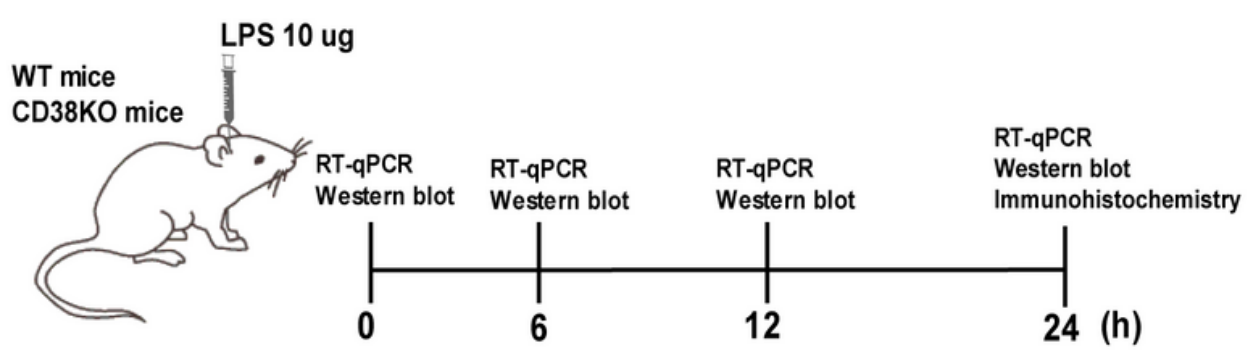

Fig. 2

$\square$ WT $\quad \square$ CD38 KO

B

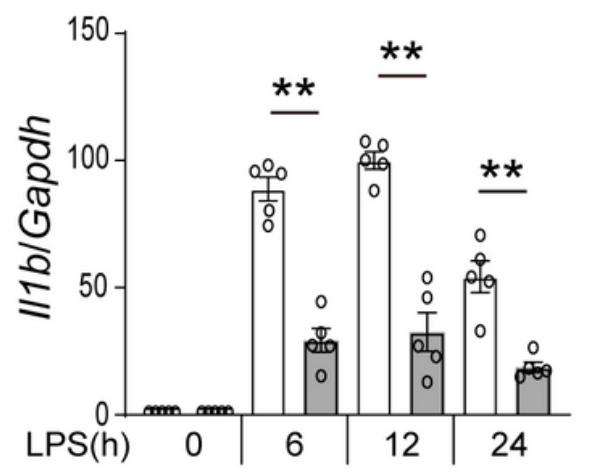

E

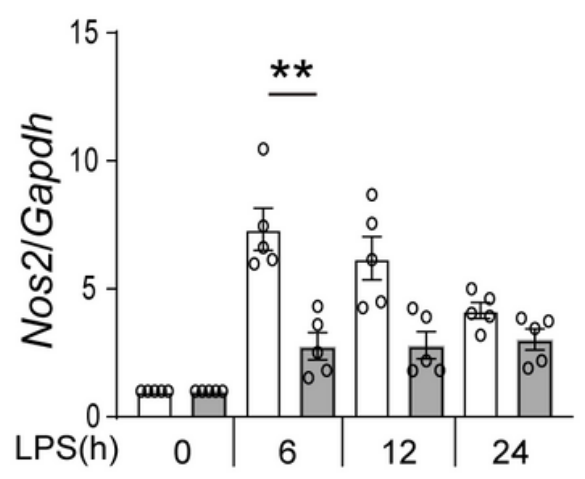

C

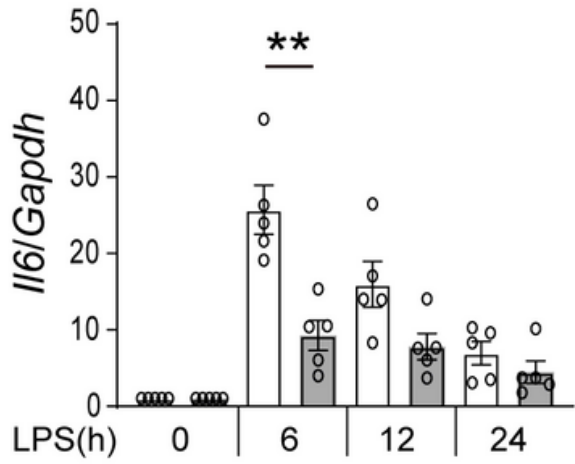

$\mathbf{F}$

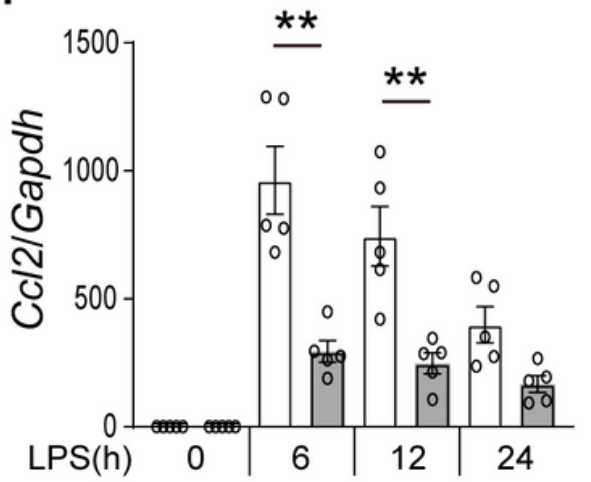

D

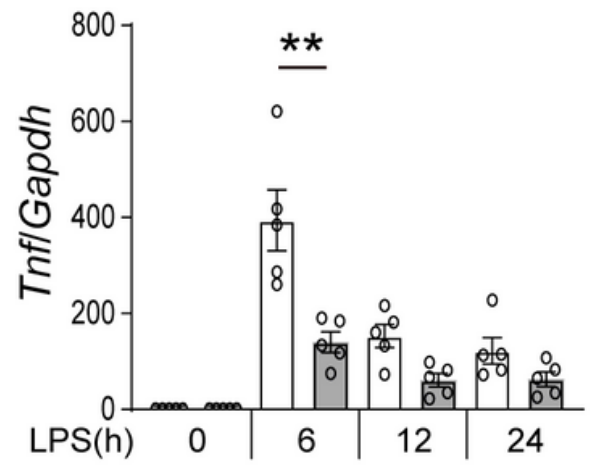

G

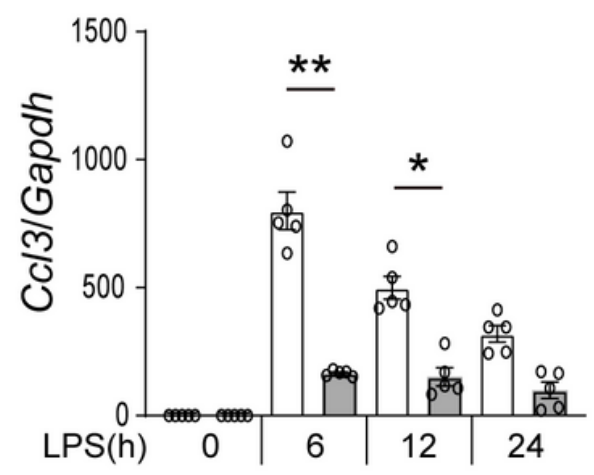

Figure 2

LPS-induced neuroinflammation was attenuated in CD38 KO mice. (a) The treatment scheme and timeline of analysis. (b-g) RT-qPCR analysis for the expression of inflammatory genes in the HPC $0,6,12$, $24 \mathrm{~h}$ after LPS injection in WT and CD38 KO mice. $\mathrm{n}=5$. Data represent means \pm SEM. $\mathrm{P}$ values are determined by two-way ANOVA followed by Scheffe's $F$ test. ${ }^{*} p<0.05$ and ${ }^{* *} p<0.01$ between WT and CD38 KO mice. 

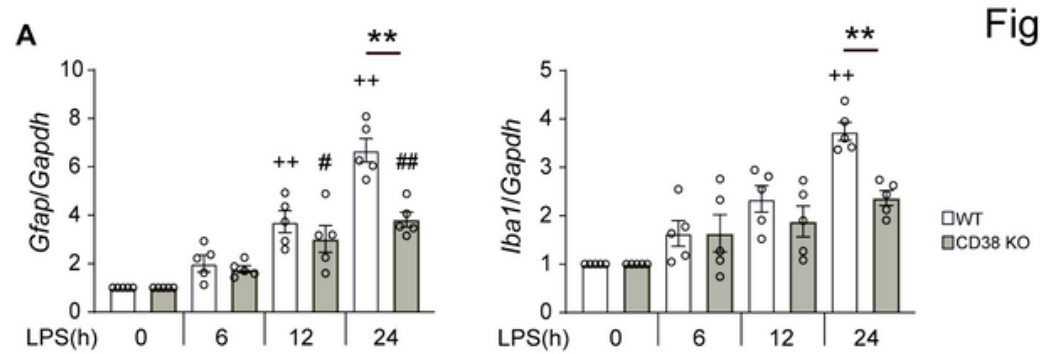

Fig. 3
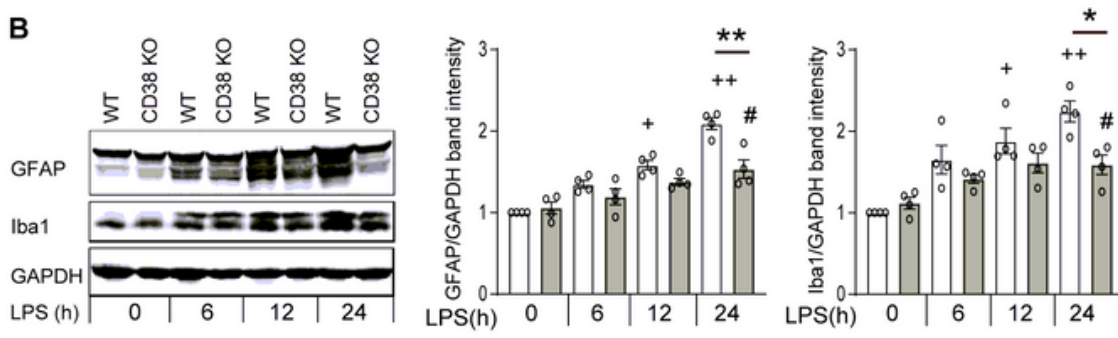

पwT

C
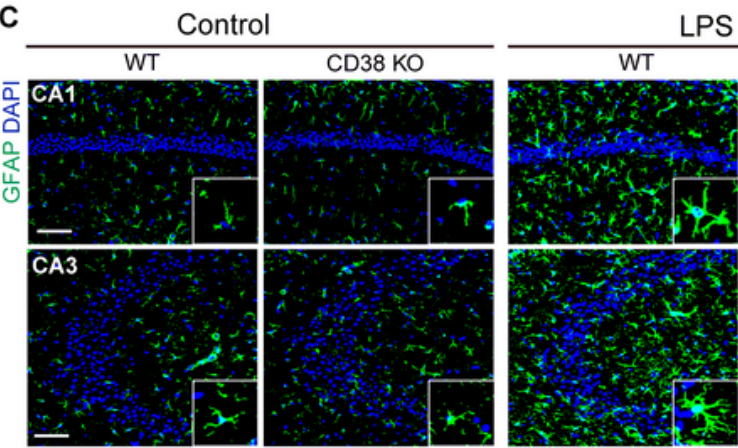

$\frac{\mathrm{CD} 38 \mathrm{KO}}{24 \mathrm{~h}}$
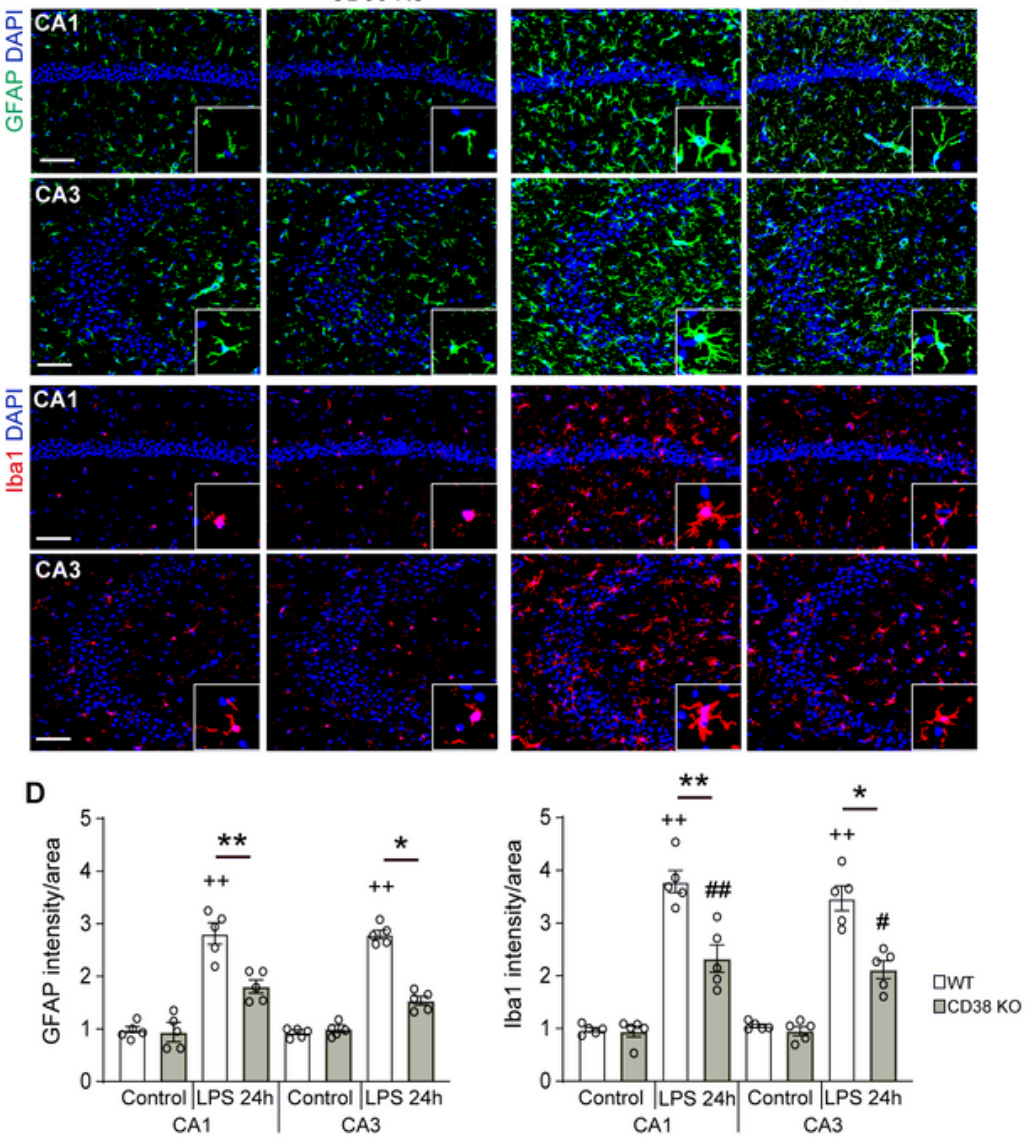

\section{Figure 3}

LPS-induced glial activation was attenuated in CD38 KO mice. (a) RT-qPCR analysis for expression levels of Gfap and Iba1 mRNA in the HPC of WT and CD38 KO mice $0,6,12,24 \mathrm{~h}$ after LPS injection. $\mathrm{n}=5$. (b) Western blotting analysis with antibodies against GFAP and Iba1 in the HPC of WT and CD38 KO mice at different time points after LPS injection. The graphs depict the relative optical density of GFAP or lba1 normalized to the loading control GAPDH. $n=5$. (c) Representative immunofluorescence images of GFAP 
(green) and Iba1 (red) of 0 and $24 \mathrm{~h}$ after LPS injection in the HPC (CA1 and CA3) of WT and CD38 KO mice. Nuclei were counterstained with DAPI. Scale bars: $100 \mu \mathrm{m}$. (d) The graphs represent the intensity of GFAP (left) and lba1 (right) 0 and $24 \mathrm{~h}$ after LPS injection in the CA1 and CA3 of WT and CD38 KO mice. $n=5$. Data represent means \pm SEM. $P$ values are determined by two-way ANOVA followed by Scheffe's $F$ test. $+p<0.05$ and $++p<0.01$ vs 0 h of LPS in the WT mice. \#p $<0.05$ and \#\#p $<0.01$ vs 0 h of LPS in the CD38 KO mice. ${ }^{*} p<0.05$ and ${ }^{* *} p<0.01$ between WT and CD38 KO mice.
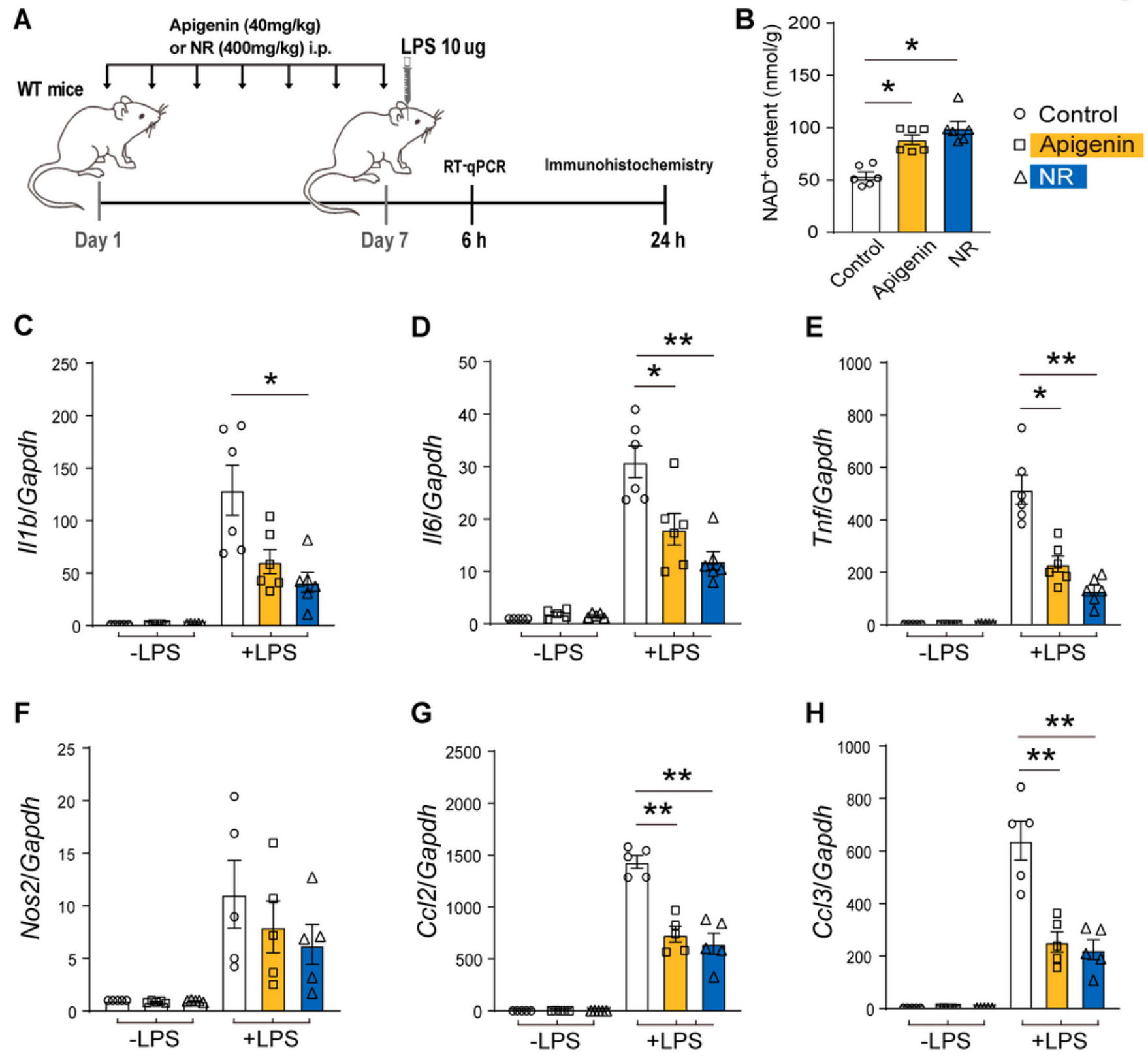

Figure 4

NR and apigenin ameliorated LPS-induced neuroinflammation. (a) The treatment scheme and timeline of analysis. (b) Evaluation of NAD levels in the HPC of WT mice after treatment with saline (-), apigenin 40 
$\mathrm{mg} / \mathrm{kg}$ or NR $400 \mathrm{mg} / \mathrm{kg}$ via i.p. injection for $7 \mathrm{~d} . \mathrm{n}=6$. Data represent means $\pm S E M$. $P$ values are determined by one-way ANOVA followed Tukey-Kramer test. * $p<0.05$ compared control. (c-h) RT-qPCR analysis for the expression of inflammatory genes in the HPC of control- or LPS injected-WT mice pretreated with saline, apigenin or NR for $7 \mathrm{~d} . \mathrm{n}=6$. Data represent means \pm SEM. $P$ values are determined by two-way ANOVA followed by Scheffe's $F$ test. ${ }^{*} p<0.05$ and ${ }^{* *} p<0.01$ vs LPS-injected control mice.

Fig. 5

A - LPS +LPS $24 \mathrm{~h}$
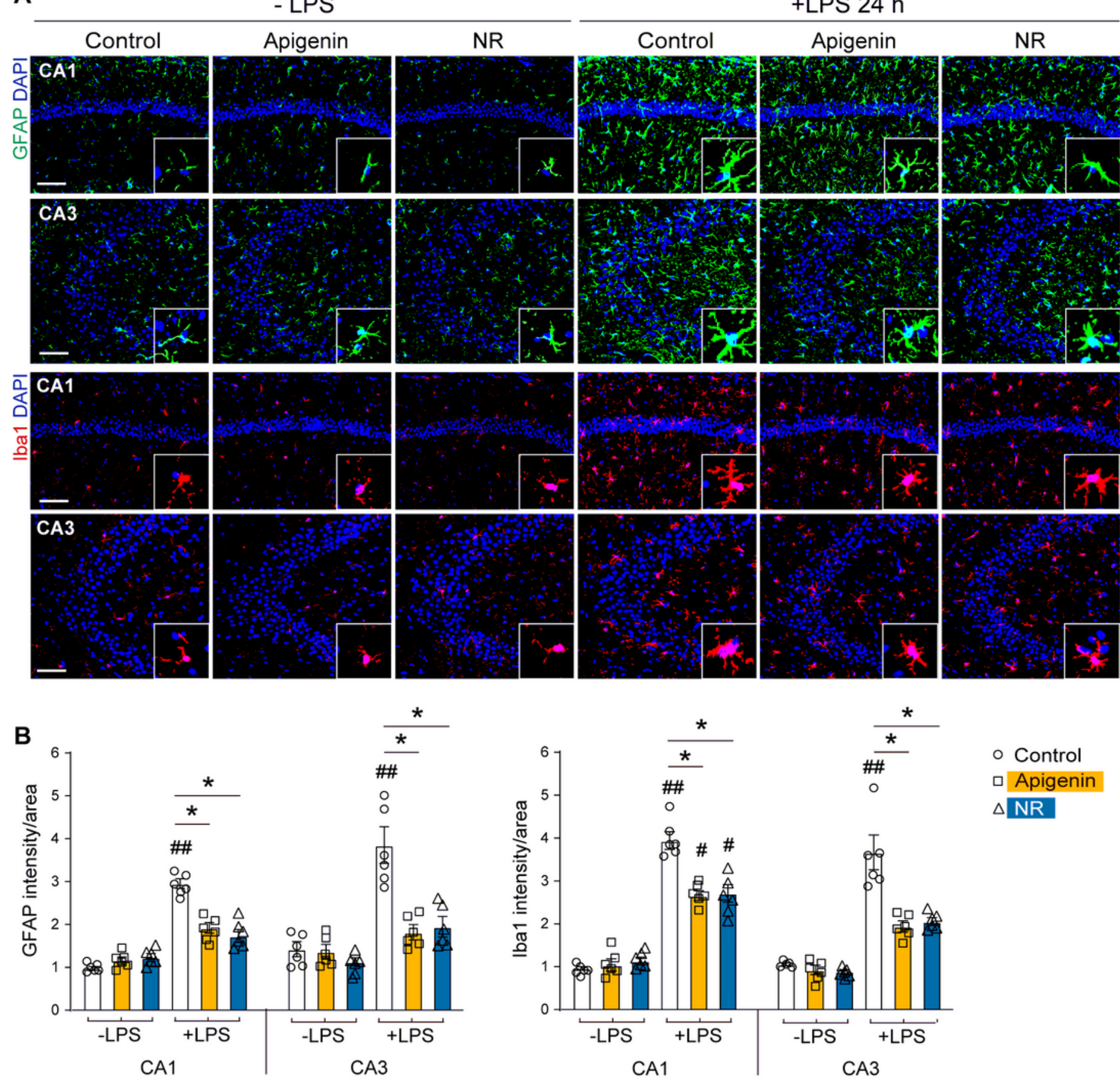

- Control $\square$ Apigenin $\triangle \mathrm{NR}$

Figure 5 
NR and apigenin ameliorated LPS-induced glial activation. (a) Representative immunofluorescence images of GFAP (green) and Iba1 (red) in the HPC (CA1 and CA3) of control- or LPS injected-WT mice pretreated with saline, apigenin or NR for $7 \mathrm{~d}$. Nuclei were counterstained with DAPI. Scale bars: $100 \mu \mathrm{m}$. (b-c) The graphs represent the intensity of GFAP and Iba1 in the HPC (CA1 and CA3). $n=6$. Data represent means \pm SEM. $P$ values were determined by two-way ANOVA followed by Scheffe's $F$ test. \#p < 0.05 and \#\#p $<0.01$ between control- and LPS-injected mice. ${ }^{\star} p<0.05$ and ${ }^{* *} p<0.01$ vs LPS-injected control mice.

Fig. 6
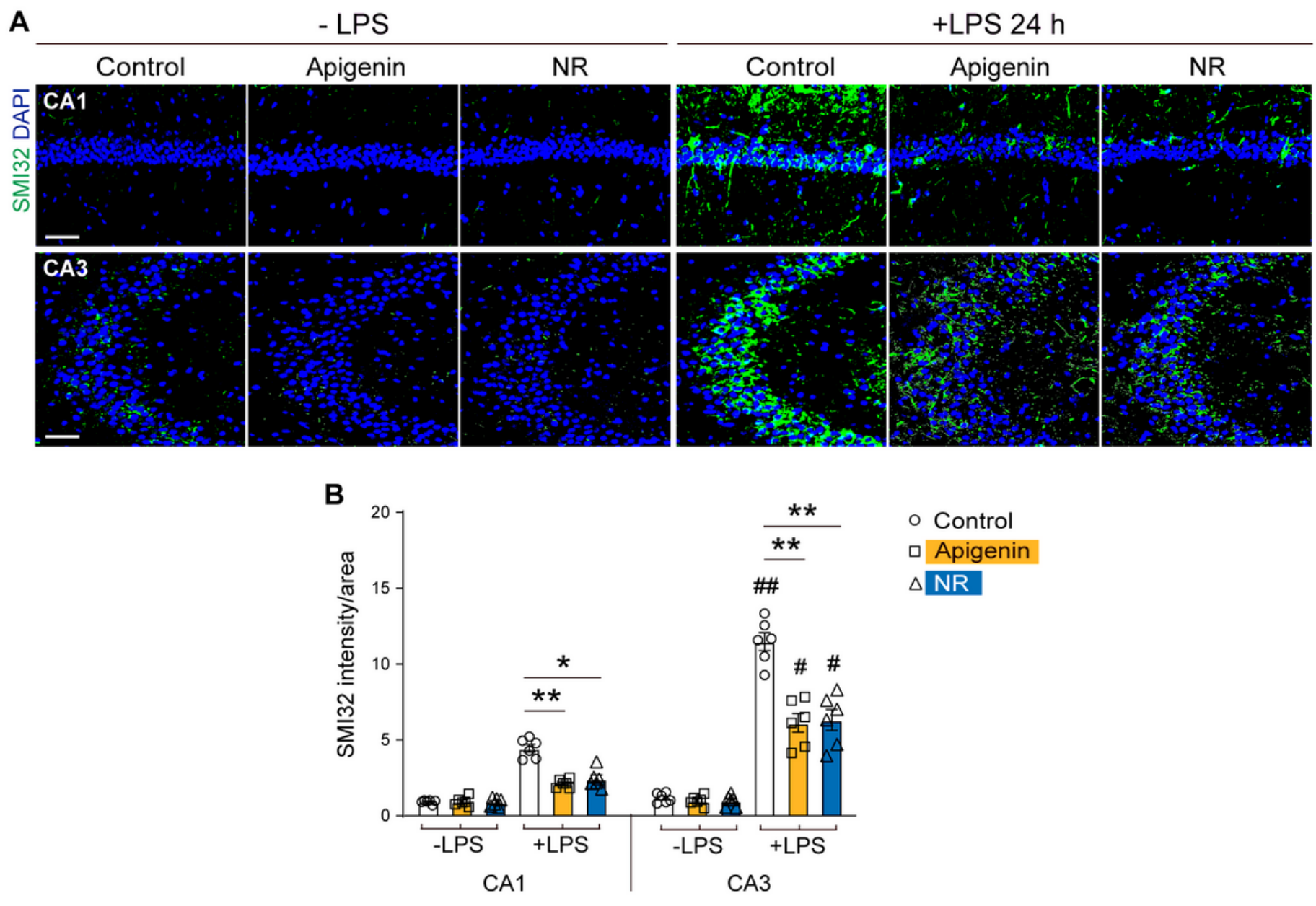

$\circ$ Control

$\square$ Apigenin

$\triangle N R$

\section{Figure 6}

NR and apigenin attenuated LPS-induced neurodegeneration. (a) Representative immunofluorescence images of SMI32 in the HPC (CA1 and CA3) of control- or LPS injected-WT mice pretreated with saline, apigenin or NR for $7 \mathrm{~d}$. Nuclei were counterstained with DAPI. Scale bars: $100 \mu \mathrm{m}$. (b) The graphs represent the intensity of SMI32 in the HPC (CA1 and CA3). $n=6$. Data represent means \pm SEM. $P$ values are determined by two-way ANOVA followed by Scheffe's $F$ test. ${ }^{*} p<0.05$ and ${ }^{* *} p<0.01$ vs LPS injected control mice. $\# p<0.05$ and \#\#p $<0.01$ between control- and LPS-injected mice. ${ }^{*} p<0.05$ and ${ }^{* *} p<0.01$ vs LPS-injected control mice. 
Fig. 7
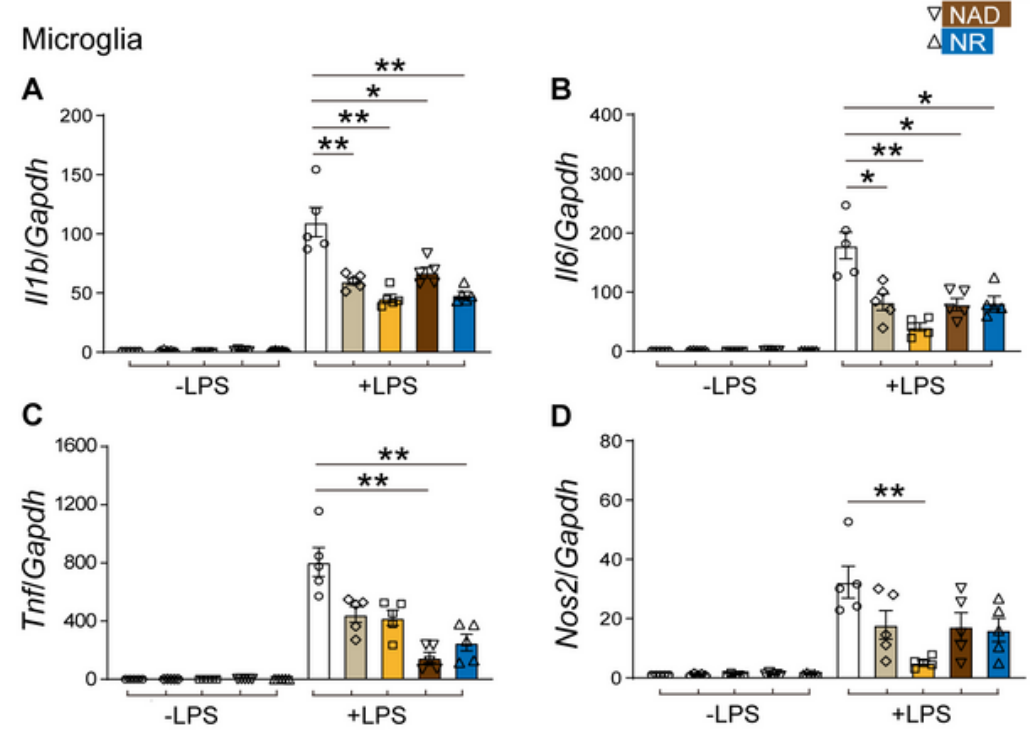

\section{Astrocyte}

E
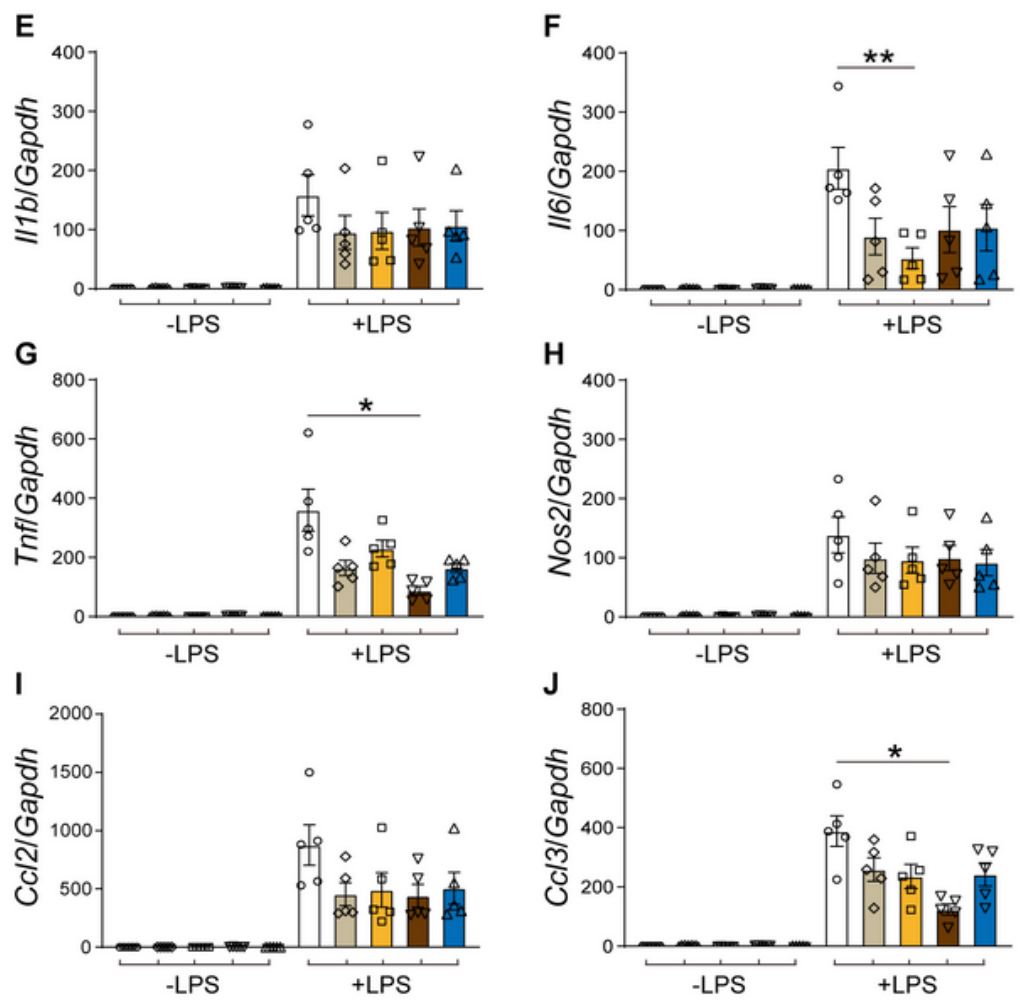

\section{Figure 7}

$\mathrm{NR}$, apigenin and 78c reduced inflammatory response in vitro. RT-qPCR analysis for the expression levels of inflammatory genes in glial cultures. (a-j) Microglia (a-d) or astrocyte (e-j) cultures were treated with saline, 78c, apigenin, NAD+ or NR for $4 \mathrm{~h}$, then stimulated with LPS $(100 \mathrm{ng} / \mathrm{ml})$ for $6 \mathrm{~h} . \mathrm{n}=6$. Data represent means \pm SEM. P values are determined by two-way ANOVA followed Scheffe's $F$ test. ${ }^{*} p<0.05$ and ${ }^{* *} \mathrm{p}<0.01$ vs LPS-treated control cells. 
Fig. 8
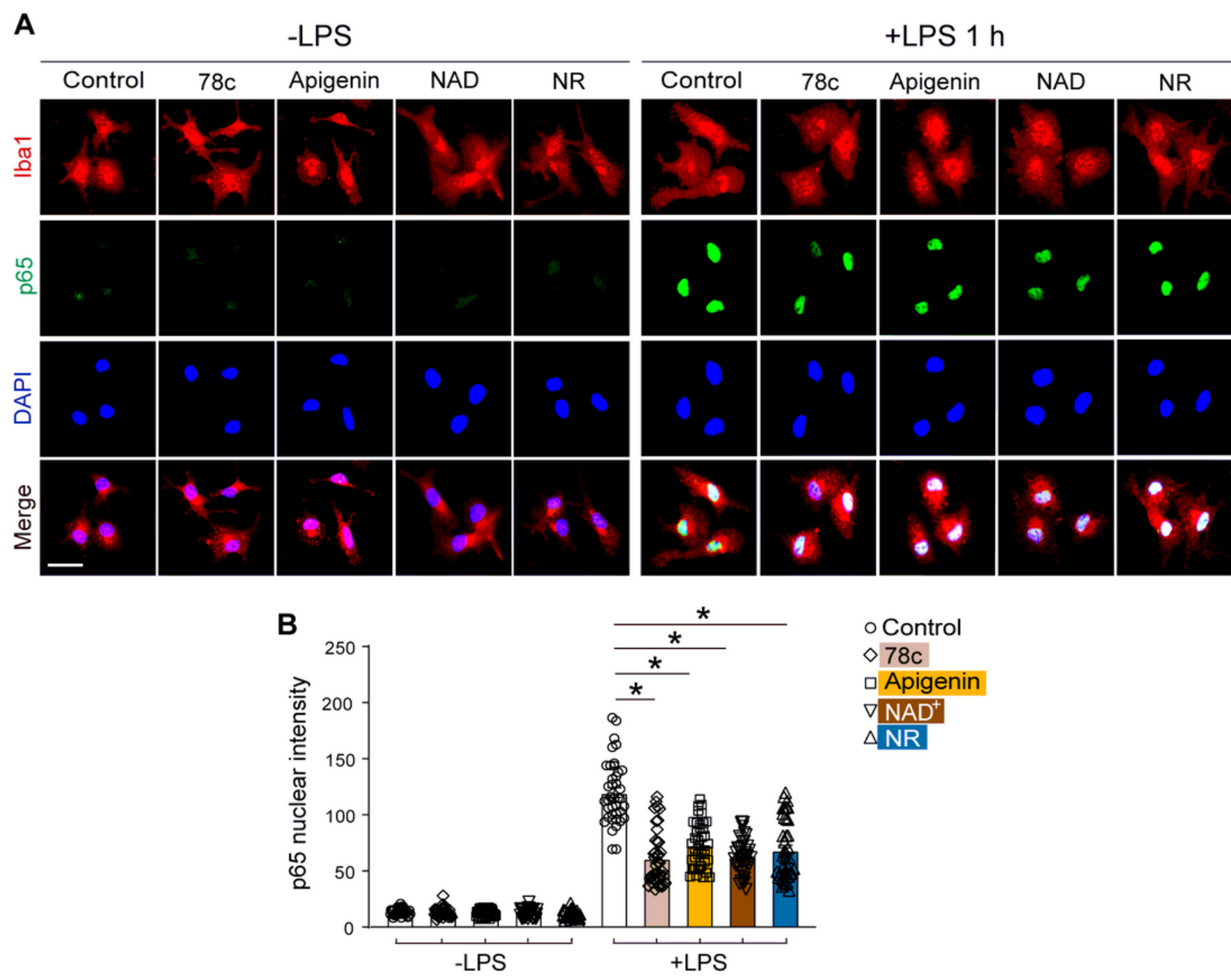

\section{Figure 8}

NR, apigenin and 78c suppressed NF-KB signaling pathway. (a) Cultured microglia were treated with 78c, apigenin, NAD+ or NR for $4 \mathrm{~h}$, then stimulated with LPS $(100 \mathrm{ng} / \mathrm{ml})$ for $1 \mathrm{~h}$. After fixation, cells were subjected to immunohistochemistry of p65 and Iba1. Nuclei were counterstained with DAPI. Scale bar: 50 $\mu \mathrm{m}$. (b) The graphs represent the intensity of p65 in the nucleus. Fifty cells per condition were analyzed, from four independent experiments. Data represent means \pm SEM. $P$ values are determined by two-way ANOVA followed by Scheffe's $F$ test. * $p<0.05$ vs LPS-treated control cells.

\section{Supplementary Files}

This is a list of supplementary files associated with this preprint. Click to download. 
- NADLPSTableS1primerqPCR.docx

- figS1.tif

- figS2.tif

- figS3.tif 